\title{
Individual and contextual determinants of the duration of diarrhoeal episodes in preschool children: a longitudinal study in an urban setting
}

C. A. S. T. SANTOS ${ }^{1,2 *}$, A. STRINA ${ }^{1}$, L. D. AMORIM ${ }^{3}$, B. GENSER ${ }^{1,4}$, A. M. O. ASSIS ${ }^{5}$, M. S. PRADO ${ }^{1}$ AND M. L. BARRETO $^{1}$

${ }^{1}$ Instituto de Saúde Coletiva, Federal University of Bahia, Salvador, Brazil

${ }^{2}$ Department of Exact Sciences, State University of Feira de Santana, Brazil

${ }^{3}$ Department of Statistics, Federal University of Bahia, Salvador, Brazil

${ }^{4}$ Mannheim Institute of Public Health, Social and Preventive Medicine, University of Heidelberg, Heidelberg, Germany

${ }^{5}$ School of Nutrition, Federal University of Bahia, Salvador, Brazil

(Accepted 23 March 2011)

\section{SUMMARY}

This study investigated individual and contextual factors associated with the duration of diarrhoeal episodes in 693 young children living in a large Brazilian city who were followed-up for at least 3 months. The outcome is analysed as a continuous variable, by means of a hierarchical conceptual model organizing the factors in meaningful blocks. A total of 2397 episodes were recorded (median duration 2 days, interquartile range 1-3 days). Low percentage of households connected to the sewerage system in the neighbourhood, low family purchasing power, high agglomeration, mother aged $<19$ years, low zinc content in child's diet, and episode severity were significantly associated with longer duration (0.26-0.69 days more). Purchasing power effect was largely mediated by environmental conditions, characteristics of the child, and hygienic behaviour. Environmental conditions acted as a possible effect modifier, enhancing the effect on duration of diarrhoea of the child not having being vaccinated against measles or breastfed for $>6$ months.

Key words: Brazil, children, duration of diarrhoea, risk factors.

\section{INTRODUCTION}

The mortality rate associated with diarrhoea in children living in developing countries has shown a tendency to decline; however, it still represents a significant health-related issue that results in approximately $1 \cdot 3$ million deaths in children aged $<5$ years annually [1]. In addition, estimated figures for

\footnotetext{
* Author for correspondence: Dr C. A. S. T. Santos, Department of Exact Sciences, State University of Feira de Santana, Av. Transnordestina s/n, Feira de Santana, Brazil - 44036-900. (Email: carlosateles@yahoo.com.br)
}

morbidity remain unchanged at around $3 \cdot 2$ episodes/ child annually [2].

An episode of diarrhoea is an event that varies in duration and may be classified as acute ( $\leqslant 14$ days) or persistent (>14 days) diarrhoea [3]. This definition has allowed the identification of potential risk factors involved in episodes of persistent diarrhoea, such as inadequate diet, short duration of breastfeeding, poor nutritional status, micronutrient deficiency, inadequate hygiene behaviour and precarious socioenvironmental and sanitary conditions, among others [4-9]. Despite these findings, knowledge regarding 
diarrhoeal episodes of longer duration remains incomplete. For this reason, other methods of investigation have been developed, in which the duration of episodes is treated as a continuous response variable [10-12]. We present the results of a longitudinal study conducted in Brazil with the aim of investigating the individual and contextual determinants of the duration, treated as a continuous variable, of episodes of diarrhoea in preschool-age children, using a hierarchical conceptual model that allowed us to measure the overall effects and their non-mediated (or direct) hierarchical components.

\section{MATERIAL AND METHODS}

\section{Study design}

The study was conducted between October 2000 and January 2002, and involved a sample of preschool-age children living in sentinel areas of the city of Salvador, a large urban centre of around 2.4 million inhabitants in northeastern Brazil. Details of the sampling procedure have been described elsewhere [13]. Briefly, 'sentinel areas' were delimited by aggregating adjacent census districts with similar socioeconomic and sanitary characteristics, and an original sample of 30 sentinel areas was randomly selected to represent the different income levels and sanitary conditions present in the city at that time. In each area, a random list of children aged $<3$ years was established at the beginning of the study, and the children were sequentially enrolled in this study as an open cohort. Data on the occurrence of diarrhoea were collected during twice-weekly visits with the use of questionnaires that were completed during interviews with the children's mothers or caregivers. The data obtained referred to the 3-4 days preceding the interview.

The 23 sentinel areas included in the present study, with a total of about 11000 dwellings, refer to those in which there was no public sewage system. A total of 1233 children were enrolled over the first 10 months of the study. Of these, 693 children having at least one episode of diarrhoea and followed-up for at least 90 days were considered for analysis. A day of diarrhoea was defined as the occurrence of $\geqslant 3$ more watery or soft stools within a $24-\mathrm{h}$ period $[14,15]$, and a diarrhoea episode was identified by a minimum 3-day diarrhoea-free gap (following our definition of day of diarrhoea) to mark the beginning of a new episode [16]. The study endpoint was the duration of episodes, defined as a continuous variable.

\section{Conceptual model and study variables}

A hierarchical conceptual model, reflecting our proposed causal frame of diarrhoea, was established to map the determinants of the duration of diarrhoeal episodes. It included contextual factors (those referring to the sentinel areas in which the children resided) $[17,18]$ and individual factors, that were organized hierarchically into four blocks in two levels, in accordance with their proximal-distal relationships to outcome [19-21] (Fig. 1). This strategy allowed us to estimate the overall effects and their non-mediated (direct) components.

Socioeconomic factors occupied the most distal level, and the second level included more proximal routes: environmental determinants (block 2), characteristics of the child (block 3 ) and hygienic behaviours (block 4). Most of the variables in blocks 1-3 were collected only once, at the beginning of followup, using a previously codified and standardized questionnaire. Data regarding mother's marital status and education level, presence of streams or ditches close to the home, quality of floor, sewage disposal system and presence of an indoor toilet were collected at least twice during the study, using supplementary questionnaires. Anthropometric measurements were obtained at three different time points (at the beginning of the study, at 6 months, and at 12 months follow-up).

In block 1, family purchasing power was defined by the possession of selected goods (washing machine, microwave oven, telephone and computer, etc.), and was subsequently dichotomized into low $(<0 \cdot 17)$ or fair/good $(\geqslant 0 \cdot 17)$ in accordance with the median value calculated.

The contextual variables in block 2 (index of environmental conditions and percentage of homes connected to the sewage system) were based on data obtained during previous field surveys on technical and operational aspects concerning water supply system, sewage system, drainage system and garbage collection system, details of which have been published previously [22, 23]. The percentage of households connected to the sewage system was classified into quartiles as very low $(<34 \cdot 1 \%)$, low $(\geqslant 34 \cdot 1 \%$ to $<47 \cdot 2 \%)$, normal $(\geqslant 47.2 \%$ to $<55.1 \%$ ) or good $(\geqslant 55 \cdot 1 \%)$.

From a single-occasion dietary survey by 24 -h recall [24], conducted by nutritionists and applied to the children's mothers or caregivers, the daily consumption of zinc, vitamin A and retinol was estimated 


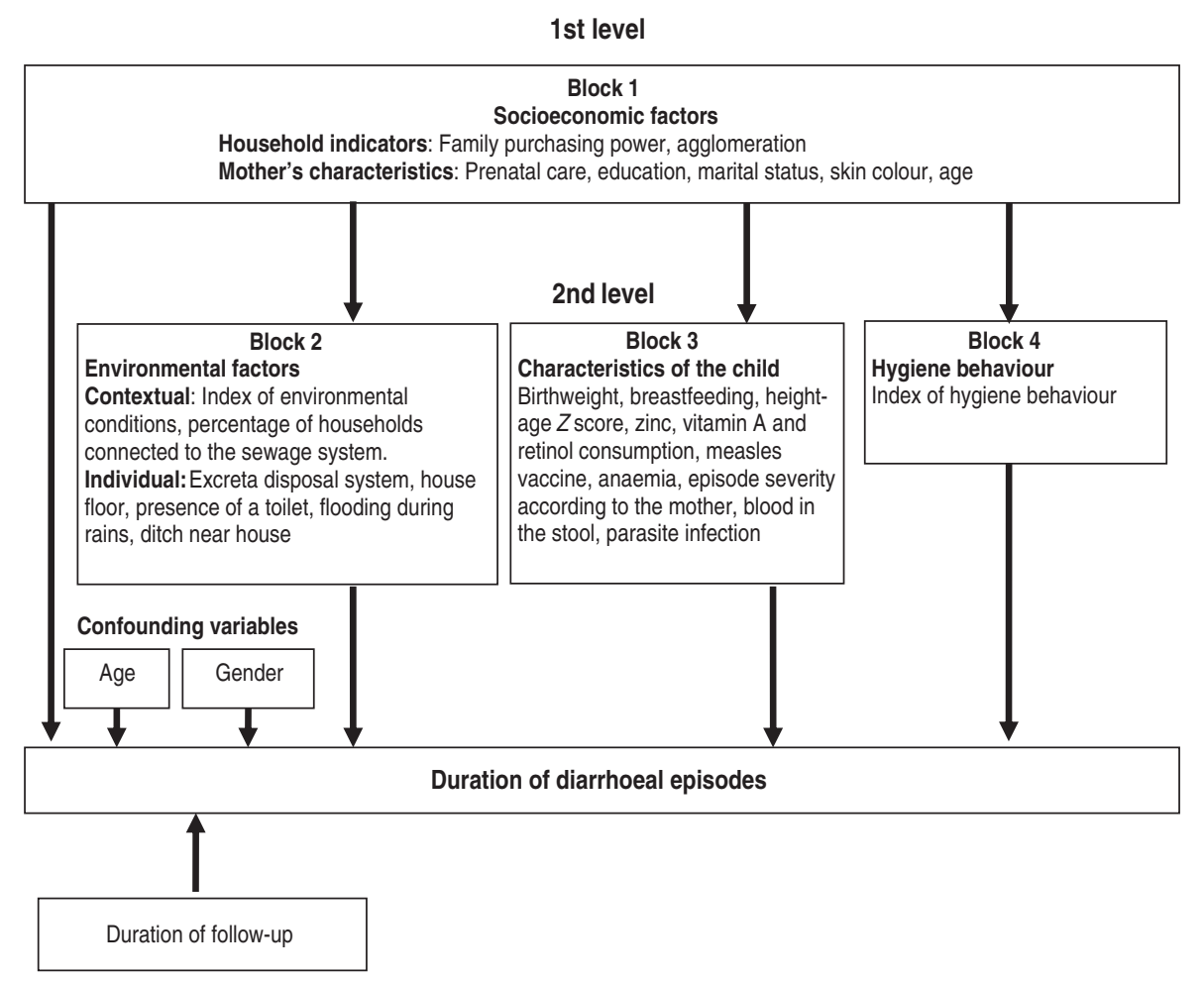

Fig. 1. Hierarchical conceptual model.

[25]. Their median levels $(3.49 \mathrm{mg}, 1705 \mu \mathrm{g}, 448 \mu \mathrm{g}$, respectively) were used as cut-off values for classifying the children (block 3 ). The severity of the diarrhoea episode, according to the perception of the mothers/caregivers, was considered to represent the child's state of health on the first day of the episode. The anthropometric indicator height/age (H/A) and weight/age (W/A), expressed as $\mathrm{H} / \mathrm{A}$ and $\mathrm{W} / \mathrm{A} Z$ scores, were calculated using the ANTHRO software program (CDC/WHO, 1990). Stool samples, collected on a single occasion, were examined using the Kato-Katz method [26] to identify and quantify Trichuris trichiura, Ascaris lumbricoides and Ancylostomatidae eggs. Giardia lamblia cysts were identified by sedimentation technique. Haemoglobin levels were measured with a portable haemoglobinometer (HemoCue AB, Sweden), and a cut-off value of $11 \mathrm{~g} / \mathrm{dl}$ was employed to classify a child as anaemic [27] (block 3). The individual hygiene behaviour score (block 4) was constructed from 33 forms of hygienic [15] or unhygienic [18] behaviour by the child or his/her caretaker, observed during the home visits [28].

This study was approved by the Research Ethics Committee of the Federal University of Bahia. The children were only included in the study after the parents or guardians had read and signed a statement of free and informed consent. Whenever necessary, the field workers counselled the mothers regarding seeking healthcare services.

\section{Statistical analysis}

In the bivariate and multivariate analyses, the duration of diarrhoeal episodes was modelled through gamma generalized linear model (GLM) equations for population mean response with identity link function. This method can efficiently deal with asymmetric and correlated continuous data [29-31]. The Huber sandwich estimator was used to correct possible violations of non-independence and misspecification of the probability distribution [30]. In the bivariate analyses, missing data of explanatory variables were treated as a separate category $[10,19]$, except for $\mathrm{H} / \mathrm{A}$ and $\mathrm{W} / \mathrm{A} Z$ scores, whose missing values were imputed with the modal value [32]. In all multivariate models, missing values for explanatory variables were all imputed with their modal values.

An effect-decomposition strategy was applied for multivariate analysis [20]. For each block of potential determinants, we used a backward elimination procedure to select the significant determinants $(P \leqslant 0 \cdot 10)$, and only these were admitted to the following multivariate stage, where several GLM equations for the 
Table 1. Incidence and duration of diarrhoeal episodes, by age

\begin{tabular}{|c|c|c|c|c|}
\hline \multirow[b]{2}{*}{$\begin{array}{l}\text { Age group } \\
\text { (months) }\end{array}$} & \multicolumn{2}{|l|}{ Incidence } & \multicolumn{2}{|c|}{$\begin{array}{l}\text { Episode duration } \\
\text { (days) }\end{array}$} \\
\hline & $\begin{array}{l}\text { Episodes/child } \\
\text { per year }\end{array}$ & $95 \% \mathrm{CI}$ & Median & IQR \\
\hline $0-6$ & $4 \cdot 77$ & $3 \cdot 02-7 \cdot 99$ & 2 & $1-3$ \\
\hline $7-12$ & $5 \cdot 87$ & $5 \cdot 07-6 \cdot 83$ & 2 & $1-4$ \\
\hline $13-18$ & $4 \cdot 90$ & $4 \cdot 36-5 \cdot 53$ & 2 & $1-4$ \\
\hline $19-24$ & 3.65 & $3 \cdot 22-4 \cdot 15$ & 2 & $1-3$ \\
\hline $25-30$ & $2 \cdot 82$ & $2 \cdot 48-3 \cdot 22$ & 2 & $1-3$ \\
\hline $31-35$ & $2 \cdot 05$ & $1 \cdot 75-2 \cdot 40$ & 1 & $1-3$ \\
\hline$\geqslant 36$ & $1 \cdot 31$ & $1 \cdot 08-1 \cdot 61$ & 1 & $1-2$ \\
\hline Total & $3 \cdot 13$ & $2 \cdot 91-3 \cdot 38$ & 2 & $1-3$ \\
\hline
\end{tabular}

CI, confidence interval; IQR, Interquartile range.

population mean response were sequentially fitted by including the blocks step-by-step according to the predefined hierarchy. This methodology allowed us to estimate the mean increase (or decrease) of duration of diarrhoeal episodes $(\beta)$ compared to the reference category of a given variable. Following our conceptual framework (Fig. 1), we fitted five gamma GLMs. Model A estimated the overall effect of the socioeconomic determinants. Models B, C and D, which included the determinants of blocks 2-4, respectively, estimated the effect of the socioeconomic determinants not mediated by the corresponding blocks above, taken individually. Model $\mathrm{E}$ estimated the effect of the socioeconomic determinants not mediated simultaneously by the determinants of blocks $2-4$, as well as the overall effects of blocks 2-4. All models were adjusted for possible confounding factors (child's gender and age at onset of the episode, and follow-up duration in months). Additional analyses were performed of possible modifying effects of contextual determinants on the association of individual determinants and duration of diarrhoea in models $\mathrm{A}$ and $\mathrm{E}$. The Anscombe residual was used to diagnose the adjustment of the gamma GLM for population mean response [29]. All statistical analyses were performed using Stata version 9.0 (StataCorp., USA).

\section{RESULTS}

The study population consisted of 693 children (53.8\% boys), aged 6-36 months at the start of the study. They were followed up for a total of 216392 child-days [median follow-up 355 days, interquartile range (IQR) 291-383) days]. A total of 2397 episodes of diarrhoea were recorded, $46.0 \%$ of which lasted for
1 day, $77 \cdot 8 \%$ for up to 3 days with $1 \cdot 1 \%$ persisting for $\geqslant 14$ days. The incidence rate was $3 \cdot 13$ episodes/ child per year (95\% confidence interval $2 \cdot 91-3 \cdot 38)$, and the median duration of the episodes was 2 days (IQR 1-3 days) overall. Both the incidence rate and duration tended to decrease with age (Table 1).

A table listing the results of the bivariate analyses of all investigated variables in each block of the conceptual model is available online (Supplementary Table 1). We identified potential risk factors in all blocks. Very poor environmental conditions, poor quality of floor, absence of a toilet in the house, presence of a ditch close to the household and a very low percentage of households connected to the sewage system, all in the environmental block, were among the variables most strongly associated with longer duration of diarrhoea (with 1.12, 0.96, 0.91, 0.89 and 0.88 days of mean increase of duration, respectively), followed, in block 1 , by maternal age $<19$ years (which, with $\beta=1 \cdot 16$, showed the highest risk), household crowding $(\beta=0.75)$ and family low purchasing power $(\beta=0 \cdot 47)$. Other factors associated with longer duration of diarrhoea were no dose of measles vaccine $(\beta=0.85), \mathrm{H} / \mathrm{A} Z$ score $<-2$ $(\beta=0 \cdot 82)$, haemoglobin level $<11 \mathrm{~g} / \mathrm{dl}(\beta=0 \cdot 67)$, episode severity $(\beta=0.55)$, breastfeeding for $<6$ months $(\beta=0 \cdot 87)$, intestinal infection by $T$. trichiura or hookworm $(\beta=0 \cdot 87, \beta=0 \cdot 80$, respectively) and a predominantly negative pattern of hygiene behaviour $(\beta=0 \cdot 78)$.

Table 2 summarizes the results of the effectdecomposition strategy of analysis, obtained by adjusting five gamma GLMs (see Methods section). Low family purchasing power, crowding, mother's young age, low percentage of households connected to the 
Table 2. Effect of the determinants of duration of diarrhoea in different models

\begin{tabular}{|c|c|c|c|c|c|c|}
\hline Determinants & & $\begin{array}{l}\text { Model A } \\
\text { (block 1) } \\
\beta(95 \% \mathrm{CI})\end{array}$ & $\begin{array}{l}\text { Model B } \\
\text { (blocks } 1 \text { and } 2) \\
\beta(95 \% \mathrm{CI})\end{array}$ & $\begin{array}{l}\text { Model C } \\
\text { (blocks } 1 \text { and 3) } \\
\beta(95 \% \mathrm{CI})\end{array}$ & $\begin{array}{l}\text { Model D } \\
\text { (blocks } 1 \text { and } 4) \\
\beta(95 \% \text { CI })\end{array}$ & $\begin{array}{l}\text { Model E } \\
\text { (blocks 1-4) } \\
\beta(95 \% \text { CI) }\end{array}$ \\
\hline \multicolumn{7}{|l|}{ Level 1} \\
\hline \multicolumn{7}{|l|}{$\begin{array}{l}\text { Block 1. Socioeconomic } \\
\text { factors }\end{array}$} \\
\hline Purchasing power* & $\begin{array}{l}\text { Fair to good } \dagger \\
\text { Low }\end{array}$ & $0.31(0.04$ to 0.59$) \$$ & $0 \cdot 22(-0.04$ to $0 \cdot 49)$ & $0.28(0.01$ to 0.55$)$ & $0.28(0.01$ to 0.54$)$ & $0 \cdot 19(-0.07$ to $0 \cdot 45)$ \\
\hline No. persons per room & $\begin{array}{l}<2 \dagger \\
\geqslant 2\end{array}$ & $0.62(0 \cdot 17$ to $1 \cdot 07) \$$ & $0.58(0.16$ to 1.00$) \neq$ & $0.61(0.16$ to 1.06$) \$$ & $0.49(0.08$ to 0.90$) \$$ & $0.49(0.08$ to 0.90$) \$$ \\
\hline Mother's age (years) & $\begin{array}{l}>19 \dagger \\
\leqslant 19\end{array}$ & $0.68(-0.03$ to 1.39$) \S$ & $0.63(0.02$ to 1.27$) \S$ & $0.56(-0.09$ to 1.20$) \S$ & $0.59(-0.08$ to $1 \cdot 25) \S$ & $0.49(-0.08$ to 1.07$) \S$ \\
\hline \multicolumn{7}{|l|}{ Level 2} \\
\hline \multicolumn{7}{|l|}{$\begin{array}{l}\text { Block 2. Environmental } \\
\text { factors }\end{array}$} \\
\hline $\begin{array}{l}\% \text { of connections to } \\
\text { sewerage* }\end{array}$ & $\begin{array}{l}\text { Good } \dagger \\
\text { Satisfactory } \\
\text { Fair } \\
\text { Low }\end{array}$ & & $\begin{array}{l}0.08(-0.21 \text { to } 0 \cdot 37) \\
0 \cdot 25(-0 \cdot 10 \text { to } 0 \cdot 60) \\
0.54(0.20 \text { to } 0 \cdot 88)\end{array}$ & & & $\begin{array}{l}0.07(-0.22 \text { to } 0.36) \\
0.23(-0.09 \text { to } 0.55) \\
0.47(0.13 \text { to } 0.80)\end{array}$ \\
\hline \multicolumn{7}{|l|}{$\begin{array}{l}\text { Block 3. Characteristics } \\
\text { of the child }\end{array}$} \\
\hline $\begin{array}{l}\text { Breastfeeding } \\
\text { (months) } \\
\text { Zinc in diet }\end{array}$ & $\begin{array}{l}\geqslant 6 \dagger \\
<6 \\
\geqslant 3 \cdot 5+\end{array}$ & & & $0.51(0.13$ to $0 \cdot 89)$ & & $0.38(-0.03$ to $0 \cdot 79) \S$ \\
\hline $\begin{array}{l}(\mathrm{mg} / 24 \mathrm{~h}) \\
\text { Measles vaccine }\end{array}$ & $\begin{array}{l}<3 \cdot 5 / \text { data missing } \\
\text { At least one dose } \dagger\end{array}$ & & & $0.30(0.04$ to 0.55$)$ & & $0.28(0.03$ to 0.53$) \$$ \\
\hline & No doses & & & $0 \cdot 29(-0 \cdot 12$ to $0 \cdot 70)$ & & $0 \cdot 25(-0 \cdot 12$ to $0 \cdot 63)$ \\
\hline Episode & $\begin{array}{l}\text { Not severe } \dagger \\
\text { Severe }\end{array}$ & & & $0 \cdot 24(-0.01$ to 0.49$) \S$ & & $0.21(-0.04$ to 0.46$)$ \\
\hline Ancylostomidae & $\mathrm{No} /$ data missing $\dagger$ & & & & & \\
\hline Haemoglobin levels & $\begin{array}{l}\text { Yes } \\
\geqslant 11 / \text { data missing } \dagger\end{array}$ & & & $0 \cdot 58(-0 \cdot 25$ to $1 \cdot 40)$ & & $0.67(-0.05$ to 1.38$) \S$ \\
\hline $\begin{array}{l}(\mathrm{g} / \mathrm{dl}) \\
\text { Block } 4 \text { Hygiene habits }\end{array}$ & $<11$ & & & $-0 \cdot 04(-0 \cdot 29$ to $0 \cdot 20)$ & & $-0 \cdot 07(-0 \cdot 31$ to $0 \cdot 16)$ \\
\hline Hygiene behaviour\| & $\begin{array}{l}\text { Positive/intermediate } \dagger \\
\text { Negative }\end{array}$ & & & & $0.40(0.01$ to 0.79$) \$$ & $0 \cdot 25(-0 \cdot 11$ to $0 \cdot 62)$ \\
\hline
\end{tabular}

Shaded cells indicate best models for levels 1 and 2.

* See Methods section - Conceptual model and study variables.

$\uparrow$ Reference category.

$\$ P \leqslant 0 \cdot 05$.

$\S P \leqslant 0 \cdot 10$.

|| Strina et al. [28].

$0.25(-0.10$ to 0.60$)$

$0.54(0.20$ to 0.88$)$ t 
sewage system, low consumption of zinc, and severity of the episode according to the perception of mother/ caregiver were all significantly associated with increasing duration of diarrhoeal episodes (models A and E). Interestingly, the effects of the socioeconomic determinants on duration of diarrhoea decreased after adjusting for variables in blocks $2-4$. The effect of family purchasing power $(\beta=0 \cdot 31)$ decreased after adjusting for variables in block $2(\beta=0 \cdot 22)$ or, less so, in block $3(\beta=0 \cdot 28)$, crowding effect $(\beta=0 \cdot 62)$ decreased after adjusting for hygiene behaviour ( $\beta=0 \cdot 49)$, and mother's young age effect $(\beta=0 \cdot 68)$ decreased after adjusting for variables in block 3 $(\beta=0 \cdot 56)$ and block $4(\beta=0 \cdot 59)$.

In the multivariate analyses including interaction terms (extensions of models $\mathrm{A}$ and $\mathrm{E}$; data not shown), significant product terms were found between the percentage of households connected to the sewage system (contextual variable), and two individual variables, measles vaccine status and breastfeeding. The overall effects of no dose of vaccine and being breastfed for $<6$ months were -0.08 and 0.43 days, respectively, when the percentage of households connected to the sewage system was good, and 0.57 and 0.73 days, respectively, when the percentage of households connected was very low.

\section{DISCUSSION}

This study aimed to identify factors associated with the duration of diarrhoeal episodes. Unlike most longitudinal studies in which duration is treated dichotomously (acute episodes vs. persistent episodes), this is one of the few studies in which the episode duration was treated as a continuous variable [10, 28]. In fact, the recommended cut-off point of $\geqslant 14$ days used to define persistent episodes of diarrhoea [3] is to a certain extent arbitrary, since there is no convincing evidence that this represents a subgroup completely apart from that of the acute episodes [4, 10]. Moreover, estimates of risk associated with episodes of longer duration may be difficult to assess through a categorical approach, when those episodes represent just a small proportion of the total, as is often the case.

A hierarchical model was used, with the block of socioeconomic determinants occupying the distal lev$\mathrm{el}$, and the environmental determinants, along with those related to biological characteristics of the children and to hygienic habits, occupying the proximal level. The effect-decomposition analytical strategy allowed us to extract the non-mediated (or direct) components of the overall effects, under the assumption of the absence of confounding at the level of the intermediate variables [19]. However, this potential limitation is mitigated by the fact that our model included a wide range of factors potentially acting on the duration of diarrhoeal episodes and grouped them in meaningful blocks, thus making it unlikely that unobserved factors are associated with both an intermediate block and outcome.

Due to the asymmetrical distribution of episode duration as a continuous variable, the dependence arising from recurrent episodes in the same individual, and our interest in duration in its natural scale and not in ratios, the gamma GLM for population mean response with identity link function was applied in the bivariate and hierarchical analyses.

Bivariate analysis identified significant determinants of duration of diarrhoea in each of the four blocks: reduced purchasing power, crowding, low level of education, and unmarried mother (block 1); low or fair proportion of dwellings connected to the sewage system, presence of a stream or a ditch near the house, and poor quality of floor (block 2); breastfeeding $<6$ months, episode severity according to mother/caregiver, no measles vaccine, low haemoglobin level and hookworm infection (block 3); and negative hygiene behaviours in block 4 (Supplementary Table 1). Most of these factors remained significant in intra-block analyses (data not shown).

In our analysis, the overall effects of the socioeconomic factors ranked among the strongest determinants of duration of diarrhoea (Table 2, model A). They were partly mediated, however, by proximal variables (Table 2, model E): the low purchasing power effect was in part explained by environmental, child-related or hygiene behaviourrelated variables, the crowding effect was in part explained by hygienic negative behaviours, and the effect of young age of mother was reduced by child-related variables or hygienic negative behaviour (Table 2, models B, C, D).

A low or very low proportion of dwellings connected to the sewage system was associated with a longer duration of episode, as was hookworm infection (Table 2, model E). Unlike the findings of Lima et al. [33], no statistically significant association was found between intestinal infections by $G$. lamblia and the duration of diarrhoeal episodes.

A noticeable, although non-significant, association was found between duration of diarrhoea and 
breastfeeding for $<6$ months, in line with results from other studies [10, 28, 34] (Table 2, model E). A low intake of zinc, despite the limitations of the measure used [25], was also associated with longer episodes, a finding consistent with zinc supplementation being reported to significantly reduce duration of diarrhoea in children [9, 35]. Few studies have been conducted to evaluate the association between hygiene behaviour and duration of episodes of diarrhoea. In the present investigation, predominantly negative behaviours contributed to increasing the duration. These findings are consistent with results from other studies that have reported longer episodes of diarrhoea resulting from the use of dirty utensils, the mother or child not washing hands after using the toilet, or food remaining unprotected for long periods of time [4, 6, 10, 28].

Sanitary conditions (percentage of households connected to the sewage system) were found to constitute a potential modifier of the effect of measles vaccine and breastfeeding on duration of diarrhoea. These results are in agreement with the findings of other studies that have reported the protective role of measles vaccine [34, 36, 37] and breastfeeding [4, 10] on duration of diarrhoea in areas where the sanitation infrastructure is poor [38].

Although longitudinal prevalence of diarrhoea is considered a better predictor than incidence of mortality associated with childhood diarrhoea [39], it still ignores the dimension represented by duration, and treats, for example, a single long episode the same way as two or more shorter episodes with an equal overall duration, thus overlooking the importance of the cumulative effect of the days with diarrhoea experienced by children suffering from a prolonged episode [33]. Studying the duration of the episodes allows us to enrich with further elements the epidemiology of diarrhoea.

Despite the time elapsed since the study was undertaken, and the changes that occurred in the meantime in the local situation (e.g. improvement of sanitation and introduction of rotavirus vaccine), our investigation is still of relevance, for at least two reasons. First, for future comparison with the present situation in Salvador; and second, because there are numerous places worldwide where the present situation is similar to the situation that prevailed in Salvador some years ago.

In conclusion, the results of this study suggest that when an episode of diarrhoea occurs, its duration is affected by the socioeconomic conditions of the family and by the environmental and sanitary infrastructure, as well as by nutritional and immunological factors, and that the context acts as a potential modifier of the effect of some factors.

\section{NOTE}

Supplementary material accompanies this paper on the Journal's website (http://journals.cambridge.org/ hyg).

\section{ACKNOWLEDGEMENTS}

Financial support for the study was provided by the PRONEX Centres of Excellence Program, CNPq, Brazilian Federal Government (Grant 661086/ 1998-4) and the Department of Infrastructure, State Government of Bahia. The authors thank the field work team and the families that participated in the study.

\section{DECLARATION OF INTEREST}

None.

\section{REFERENCES}

1. Black RE, et al. Global, regional, and national causes of child mortality in 2008: a systematic analysis. Lancet 2010; 375: 1969-1987.

2. Kosek M, Bern C, Guerrant RL. The global burden of diarrhoeal disease, as estimated from studies published between 1992 and 2000. Bulletin of the World Health Organization 2003; 81: 197-204.

3. WHO. Persistent diarrhoea in children in developing countries: memorandum from a WHO meeting. Bulletin of the World Health Organization 1988; 66: 709-717.

4. Mahalanabis D, et al. Prognostic indicators and risk factors for increased duration of acute diarrhoea and for persistent diarrhoea in children. International Journal of Epidemiology 1991; 20 : 1064-1072.

5. Lima AA, Guerrant RL. Persistent diarrhea in children: epidemiology, risk factors, pathophysiology, nutritional impact, and management. Epidemiologic Reviews 1992; 14: 222-242.

6. U KM, et al. Risk factors for the development of persistent diarrhoea and malnutrition in Burmese children. International Journal of Epidemiology 1992; 21: 1021-1029.

7. Black RE. Persistent diarrhoea in children of developing 584 countries. Pediatric Infectious Disease Journal 1993; 12: 751-761.

8. Mahmud MA, et al. Sociodemographic, environmental and clinical risk factors for developing persistent 
diarrhoea among infants in a rural community of Egypt. Journal of Health Population and Nutrition 2001; 19: 313-319.

9. Bitarakwate E, Mworozi E, Kekitiinwa A. Serum zinc status of children with persistent diarrhoea admitted to the diarrhoea management unit of Mulago Hospital, Uganda. African Health Sciences 2003; 3: 54-60.

10. Mirza NM, et al. Risk factors for diarrheal duration. American Journal of Epidemiology 1997; 146: 776-785.

11. Checkley W, et al. Effect of water and sanitation on childhood health in a poor Peruvian peri-urban community. Lancet 2004; 363: 112-118.

12. Strina A, et al. Childhood diarrhea symptoms, management and duration: observations from a longitudinal community study. Transactions of the Royal Society of Tropical Medicine and Hygiene 2005; 99: 407-416.

13. Teixeira MG, et al. Sentinel areas: a monitoring strategy in public health. Cadernos de Saúde Publica 2002; 18: 1189-1195.

14. Barreto ML, et al. Effect of vitamin A supplementation on diarrhoea and acute lower-respiratory-tract infections in young children in Brazil. Lancet 1994; 344: 228-231.

15. Morris SS, Cousens SN, Lanata CF, Kirkwood BR. Diarrhoea - defining the episode. International Journal of Epidemiology 1994; 23: 617-623.

16. Baqui AH, et al. Methodological issues in diarrhoeal diseases epidemiology: definition of diarrhoeal episodes. International Journal of Epidemiology 1991; 20: 1057-1063.

17. Diez Roux AV. Investigating neighborhood and area effects on health. American Journal of Public Health 2001; 91: 1783-1789.

18. O'Campo P. Advancing theory and methods for multilevel models of residential neighborhoods and health [Invited commentary]. American Journal of Epidemiology 2003; 157: 9-13.

19. Genser B, et al. Risk factors for childhood diarrhea incidence: dynamic analysis of a longitudinal study. Epidemiology 2006; 17: 658-667.

20. Victora CG, et al. The role of conceptual frameworks in epidemiological analysis: a hierarchical approach. International Journal of Epidemiology 1997; 26: 224-227.

21. Ferrer SR, et al. A hierarchical model for studying risk factors for childhood diarrhoea: a case-control study in a middle-income country. International Journal of Epidemiology 2008; 37: 805-815.

22. Milroy C, Borja P, Barros FC. Evaluating sanitary quality and classifying urban sectors according to environmental conditions. Environment \& Urbanization 2001; 13: 235-255.

23. Barreto ML, et al. Evaluation of changes of sanitary conditions in sentinel areas. In: Evaluation of the Epidemiologic Impact of the Program of Environmental Sanitation of Todos os Santos Bay (Blue Bay Program). Salvador, Brasil: ISC, Federal University of Bahia, 2006, pp. 232-320.
24. Magalhães LP, Oliveira VA, Santos JM. Guidelines for estimating food consumption. Salvador, Brasil: Research Group on Nutrition and Epidemiology, Federal University of Bahia, 1996.

25. Philippi ST, Szarfarc SC, Latterza AR. Virtual Nutri, version 1.0 for Windows. São Paulo, Brasil: Department of Nutrition, Faculty of Public Health, University of São Paulo, 1996.

26. Katz N, Chaves A, Pellegrino J. A simple device for quantitative stool thick-smear technique in Schistosomiasis mansoni. Revista do Instituto de Medicina Tropical de São Paulo 1972; 14: 397-400.

27. Hunter RE, Smith NJ. Hemoglobin and hematocrit values in iron deficiency in infancy. Journal of Pediatrics 1972; 81: 710-713.

28. Strina A, et al. Childhood diarrhea and observed hygiene behavior in Salvador, Brazil. American Journal of Epidemiology 2003; 157: 1032-1038.

29. Cordeiro GM. Generalized Linear Models. Campinas, SP, Brasil: VII National Symposium on Probability and Statistics, 1996.

30. Harrell Jr. FE. Regression Modeling Strategies. New York: Springer, 2001, pp. 595.

31. Twisk JWR. Longitudinal data analysis. A comparison between generalized estimating equations and random coefficient analysis. European Journal of Epidemiology 2004; 19: 769-776.

32. Twisk JWR. Applied longitudinal data analysis for epidemiology - a practical guide. Cambridge, UK: Cambridge University Press, 2003, pp. 305.

33. Lima AA, et al. Persistent diarrhea signals a critical period of increased diarrhea burdens and nutritional shortfalls: a prospective cohort study among children in northeastern Brazil. Journal of Infectious Diseases 2000; 181: 1643-1651.

34. Mølbak K, et al. Risk factors for diarrheal disease incidence in early childhood: a community cohort study from Guinea-Bissau. American Journal of Epidemiology 1997; 146: 273-282.

35. Dutta $\mathbf{P}$, et al. Impact of zinc supplementation in malnourished children with acute watery diarrhoea. Journal of Tropical Pediatrics 2000; 46: 259-263.

36. Feachem RG, Koblinsky MA. Interventions for the control of diarrhoeal diseases among young children: measles immunization. Bulletin of the World Health Organization 1983; 61: 641-652.

37. Fine PE. Non-specific effects of measles vaccine - more grist for the mill [Commentary]. International Journal of Epidemiology 2003; 32: 116-117.

38. VanDerslice J, Popkin B, Briscoe J. Drinking-water quality, sanitation, and breast-feeding: their interactive effects on infant health. Bulletin of the World Health Organization 1994; 72: 589-601.

39. Morris SS, et al. Is prevalence of diarrhea a better predictor of subsequent mortality and weight gain than diarrhea incidence? American Journal of Epidemiology 1996; 144: 582-588. 